\title{
PROJETO EMI: ENSINO E PROJETO DE EXTENSÃO COM PARTICIPAÇÃO SOCIAL NO MUNICÍPIO DE FORQUILHINHA/SC
}

\author{
Jorge Luiz Vieira \\ Universidade do Extremo Sul Catarinense \\ jov@unesc.net \\ Evelise Chemale Zancan \\ Universidade do Extremo Sul Catarinense \\ ecz@unesc.net \\ Vanildo Rodrigues \\ Universidade do Extremo Sul Catarinense \\ vro@unesc.net
}

\begin{abstract}
Resumo
$\mathrm{O}$ artigo procura trazer ao debate a importância da extensão universitária como instrumento complementar às atividades acadêmicas de ensino de projeto de arquitetura. Destaca o papel da Universidade na disseminação de práticas projetuais com participação social ativa, por meio da extensão. $\mathrm{O}$ emprego de metodologia de participação, na elaboração do programa de projeto urbano, tem sido colocado como alternativa para que os resultados de projetos comunitários alcancem maior engajamento. Parte-se da premissa de que o grau de corresponsabilidade social, sobre qualquer espaço público, está diretamente relacionado à forma como seus cidadãos participam das decisões. O fio condutor se dá por meio de um processo mais horizontal e, portanto, menos vertical, de trocas de saberes técnicos, vernaculares e de afloramento das necessidades comunitárias sobre determinado recorte espacial. O objetivo deste trabalho é apresentar a experiência em andamento do projeto de um parque urbano em uma área de 2,53 ha, localizada em um bairro popular do município de Forquilhinha, sul de Santa Catarina. O projeto de extensão, realizado pelo Escritório Modelo Interdisciplinar de Assistência Técnica (EMI), envolveu a Universidade do Extremo Sul Catarinense (UNESC), Administração Pública local, instituição de educação especial APAE (Associação de Pais e Amigos dos Excepcionais), Cooperativa Pioneira de Eletrificação Rural (COOPERA) e a ONG "Coletivo Cultural Catavento". A metodologia compreendeu uma série de ações, destacando-se as oficinas participativas, que envolveram simultaneamente todos os agentes participantes do processo. O que se apresenta como resultado são os passos desencadeados até a realização das oficinas, os métodos de trabalho anteriores, durante e pós oficinas, o resultado programático alcançado e a resposta de projeto desenvolvida até a fase de conclusão do estudo preliminar.
\end{abstract}

Palavras chave: Extensão universitária. Projeto urbano participativo. Espaço Comunitário Multiuso.

\section{EMI PROJECT: TEACHING AND EXTENSION PROJECT WITH SOCIAL PARTICIPATION IN THE MUNICIPALITY OF FORQUILHINHA / SC}

\begin{abstract}
The article seeks to bring to the debate the importance of university extension as a complementary instrument to academic activities teaching architecture design. It highlights the role of the University in the dissemination of design practice active social participation, through extension. The use of community participation methodology, in the elaboration of the urban project program, has been considered an alternative so that the results of community projects reach greater engagement of the population. It starts from the premise that the degree of social co-responsibility, in any public space, is directly related to the way that citizens participate in decisions. The
\end{abstract}

Cidadania em Ação: Revista de Extensão e Cultura, Florianópolis (SC), v. 4, n. 1, jan./jun. 2020. 
conducting wire occurs through a more horizontal and, therefore, less vertical process, of exchanges of technical, vernacular knowledge and emergency of community needs on the previously defined spatial profile. The objective of this work is to present the ongoing experience of designing an urban park in an area of 2.53 ha, located in a popular neighborhood in the municipality of Forquilhinha, south of Santa Catarina state. The extension project, held by the Interdisciplinary Technical Assistance Model Office EMI (Escritório Modelo Interdisciplinar de Assistência Técnica), involved the "Extremo Sul Catarinense" University (UNESC), the Local Public Administration, the Institution of Special Education APAE (Associação de Pais e Amigos dos Excepcionais), the "Cooperativa Pioneira de Eletrificação Rural" (COOPERA) and NGO "Coletivo Cultural Catavento". The methodology includes a series of actions and participatory workshops, which involved all the agents participating. As a result, the steps taken until the workshops are held, the previous working methods, during and after workshops, the programmatic result achieved and the project response developed until the conclusion of the preliminary study.

Keywords: University extension. Participatory urban project. Multipurpose Community Space.

\section{PROYECTO EMI: PROYECTO DE ENSEÑANZA Y EXTENSIÓN CON PARTICIPACIÓN SOCIAL EN EL MUNICIPIO DE FORQUILHINHA / SC}

\section{Resumen}

El artículo busca llevar al debate la importancia de la extensión universitaria como instrumento complementario a las actividades académicas de enseñanza del diseño arquitectónico. Destaca el papel de la Universidad en la difusión de prácticas de diseño con participación social activa, a través de la extensión. El uso de la metodolgía de participación, em la elaboración del programa del proyecto urbano, se ha colocado como una alternativa para que los resultados de los proyectos comunitarios alcancen un mayor compromiso. Se parte de la premisa de que el grado de corresponsabilidad social, sobre cualquier espacio público, está directamente relacionado con la forma en que sus ciudadanos participan en las decisiones. El hilo conductor ocurre a través del intercambio de conocimientos técnicos y vernáculos y la aparición de necesidades de la comunidad en un perfil espacial dado. El objectivo de este trabajo es presentar la experiencia actual del proyecto de un parque urbano en un área de 2.53 ha, ubicado en un barrio popular en el municipio de Forquilhinha, al sur de Santa Catarina. El proyecto de extensión, llevado a cabo por la Oficina Modelo Interdisciplinaria de Assistencia Técnica EMI (Escritório Modelo Interdisciplinar de Assistência Técnica), la Administración Pública local, la instituición de educación especial Asociación de Padres y Amigos de Personas Excepcionales APAE (Associação de Pais e Amigos dos Excepcionais), Cooperativa Pionera de Electrificación rural (COOPERA) y la ONG "Coletivo Cultural Catavento". La metodología comprendió una serie de acciones, especialmente los talleres participativos, que involucraran a todos los agente que participaron en el processo simultáneamente. Lo que aparece como resultado son los pasos dados hasta que se llevan a cabo los talleres, loe métodos de trabajo anteriores, durante y después de los talleres, el resultado programático alcanzado y la respuesta del proyecto desarrollada hasta la conclusión del estudio preliminar.

Palabras clave: Extensión universitaria. Proyecto urbano participativo. Espacio comunitario polivalente. 


\section{INTRODUÇÃO}

A interação do meio acadêmico com a comunidade desperta o senso crítico e coloca desafios para a aplicação da criatividade e dos saberes teóricos e práticos adquiridos ao longo da formação universitária nos cursos de arquitetura e urbanismo e de engenharias. Nessa perspectiva, o Escritório Modelo Interdisciplinar de Assistência Técnica (EMI), que integra a estrutura do Programa Permanente de Extensão "Habitat + Humano, Inclusivo e Sustentável (PEHIS), da Universidade do Extremo Sula Catarinense (UNESC), trabalha as atividades extensionistas interdisciplinares em parceria com instituições locais. O Estatuto da Cidade estabelece a possibilidade de cooperação entre os governos, a iniciativa privada e os demais setores da sociedade no processo de urbanização, em atendimento ao interesse social das cidades, incluindo a possibilidade de participação das universidades por meio da extensão ou de escritórios modelos.

O EMI tem por objetivo geral propor projetos colaborativos por meio da assistência técnica gratuita, no desenvolvimento de ações que envolvam entidades representativas das comunidades locais, instituições e administração pública para viabilizar projetos de interesse social no campo da habitação e de equipamentos comunitários. A experiência aqui apresentada compreende a realização de um projeto participativo de urbanização, arquitetura, paisagismo e engenharia de um complexo de equipamentos de cultura, esporte, recreação e lazer, sobre uma área de 2,53 hectares, localizada no bairro Nova York (vide Figura 01), com abrangência sobre os bairros Ouro Negro e Vila Franca, situados a leste do centro da cidade de Forquilhinha e que somam cerca de 1.500 famílias. 
Figura 01 - Área do Projeto no Perímetro Urbano de Forquilhinha/SC

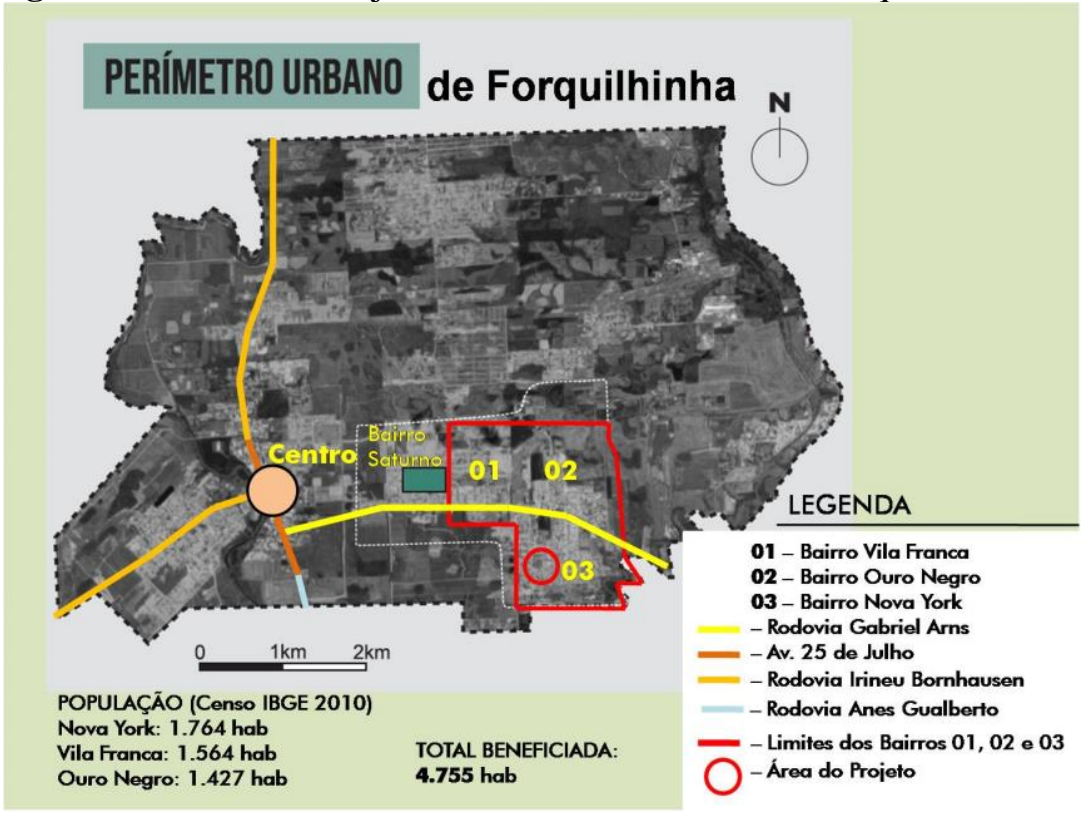

Fonte: equipe do projeto.

A metodologia aplicada ao projeto se baseou na construção coletiva do conhecimento como forma de fomentar a participação da comunidade local, diretamente beneficiada. $\mathrm{O}$ trabalho enfatiza os desdobramentos da metodologia aplicada em cada etapa do processo, desde o necessário entrosamento entre a equipe acadêmica com as lideranças locais e comunidade em geral. Até aqui, foram seis encontros com a realização de cinco oficinas participativas em sequência, das quais se apresentam o planejamento e a aplicação das dinâmicas empregadas, bem como os resultados alcançados em cada uma.

\section{METODOLOGIA}

A construção da metodologia do trabalho foi inspirada no enfoque teórico dado por Freire (2011), especialmente no que este autor coloca como saberes indispensáveis à formação crítica que insere o sujeito aprendiz como protagonista do processo de produção do conhecimento, e não mero espectador passivo em um contexto limitado pela simples transmissão de conhecimento que, é sabido, não contribui para a sua efetiva formação integral.

De certa forma, a conceituação da "Sociologia das Ausências", de Santos (2007, p. 28-29), vem de encontro a esse enfoque teórico quando, entre os cinco modos de ausências em nossa racionalidade ocidental apontados por ele, coloca como primeira a questão da monocultura do saber e do rigor. Segundo este autor, esse modo de validar 
unicamente o saber próprio da ciência ocidental desconsidera as práticas sociais que se baseiam em conhecimentos populares, levando ao "epistemicídio", ou seja, a morte de conhecimentos alternativos, reduzindo a realidade e alimenta a ignorância pela produção da inexistência e da ausência.

A percepção de Sousa aparece antes como modo de ação nas premissas colocadas por Freire (2011), que não se limitam ao enfoque acadêmico, mas sim como um método de estrutura teórica aberta, que permite incluir situações que abrangem distintos atores envolvidos no processo de ensino-aprendizagem. Nesse sentido, a Universidade se coloca como instituição que tem os meios para protagonizar experiências de construção de saberes, capaz de integrar os conhecimentos técnicos e científicos por ela produzidos com os conhecimentos da população em geral de determinada comunidade, por meio da extensão. Dessa maneira, a autonomia, conforme Freire (2011), se busca por meio de participação horizontal, o que instrui e fortalece a capacidade de autogestão na solução dos problemas comuns. No entanto, segundo Imai (2007, p. 39), essa prática só é possível por meio do consenso. Segundo ele, a aceitação das diversidades e diferenças e a busca pelo consenso dependem de um treinamento social, que se dá pela própria prática da participação.

Para Freire (2013, p. 87-125), o pensamento resulta da coparticipação de vários sujeitos sobre determinado objeto e, esta, se dá pela comunicação, onde o objeto passa a ser o mediatizador. No ato da comunicação, que se faz por meio de palavras e, acrescentaríamos, signos, deve se ter em conta o elo de fluxo entre pensamento-linguagemcontexto ou realidade. E a capacitação técnica, segundo ele, seria mais que o treinamento puro e simples, porque essa é busca de conhecimento e apropriação de procedimentos. Então, aqui podemos visualizar o sentido da extensão como o elo da Universidade com a comunidade, em que a primeira deve estabelecer os meios de comunicação para que o conhecimento acumulado em suas fronteiras seja apropriado pela sociedade, em benefício de seu desenvolvimento social, político, econômico, cultural e de bem-estar.

A questão fundamental, que se coloca em processos de construção de conhecimento coletivo, é que a metodologia seja participativa, em que se estabelecem agentes organizadores e mediadores com habilidades para possibilitar que o grupo participante possa efetivamente contribuir para a construção do que se acordou previamente como objetivos a serem alcançados por todos os envolvidos. Estabelece-se, assim, um enfoque de diálogo permanente e de valorização das experiências, saberes, crenças e culturas da comunidade para o alcance do resultado final do trabalho 
previamente definido, a partir de uma demanda surgida da própria comunidade. Nesse sentido, Pateman (1970, apud Imai, 2007, p. 42), afirma que "[...] a principal contribuição da teoria participatória deve estar em possibilitar que o foco da nossa atenção esteja voltado para as inter-relações entre os indivíduos e as estruturas de autoridade de instituições com as quais eles interagem".

Após a segunda metade do século XX, surgem vários trabalhos de autores que passam a abordar a questão da participação social em projetos de caráter público e, também, de habitação social. Segundo Imai (2007, p. 61), entre as décadas de 1960 e 70, o conceito de participação do usuário no projeto de arquitetura ganha força entre autores como Ralph Erskine, Giancarlo de Carlo, Lucien Kroll e Christopher Alexander. No Brasil, sob influência desse movimento internacional, o trabalho radical protagonizado pelo grupo Quadra, conduzido por Carlos Nelson Ferreira dos Santos, procurava enfrentar a questão da compreensão das relações sociais comunitárias de apropriação do espaço público, tendo como recortes as favelas do Rio de Janeiro, introduzindo uma metodologia interdisciplinar de busca dos significados que a população dava aos diversos espaços, que foram objeto de algumas publicações, nos anos de 1970 e 80, entre elas, o livro "Quando a Rua vira Casa", publicado em 1985.

Uma questão central na implementação de qualquer processo participativo diz respeito à assimetria que se coloca a priori, entre o conhecimento dito científico e aquele dito popular ou vernacular. Portanto, qualquer trabalho que pretenda ser participativo deve considerar este aspecto na metodologia a ser construída e trabalhada com o grupo social envolvido no processo. Sobre este aspecto Imai (2007, p. 41) observa:

O conceito básico de um processo participatório é o de que os conhecimentos
existentes entre duas ou mais partes levam-nas a uma influência mútua no
sentido de definir os diferentes aspectos do objeto da discussão. Para que isso
seja possível é necessário serem equacionadas as dificuldades de comunicação
entre o objeto imaginado (projeto) e o mundo real. Para que uma pessoa
efetivamente participe na elaboração de um projeto é necessário que ela possua
meios de compreender o que está sendo representado e possa contribuir nesse
processo. Caso contrário, o projeto participativo pode-se tornar apenas uma
forma de legitimar as decisões do projetista ou de quem detém o conhecimento
técnico (MALARD, 2002). Esse aspecto é lembrado por Sanoff (2000), ao
afirmar que a participação depende do contexto, variando em intensidade,
extensão e frequência, podendo-se encontrar dois tipos básicos de participação: a
pseudo participação e a participação genuína. A primeira é dividida entre a
"domesticação", que envolve o controle à informação e a manipulação do
processo e o "asssistencialismo", que envolve aspectos de consulta sem
transparência de poder decisório; e a segunda é dividida entre "cooperação", que
envolve aspectos de parceria e delegação de poder e o "controle" do processo por
parte do usuário. 
Nesse sentido, o processo de aproximação entre os agentes da universidade e a comunidade é muito importante, tendo sido este o ponto de partida para a definição de uma metodologia de trabalho que levasse em conta as características sociais e culturais da comunidade envolvida. A metodologia compreende os seguintes passos: 1- Formação de rede de representações de instituições locais para atuação mediadora; 2 - Reconhecimento do lugar e das principais lideranças locais; 3 - Identificação dos usuários dos espaços a serem projetados; 4 - Levantamento das demandas de programa e de espaços; 5 Levantamento planialtimétrico da área do projeto; 6 - Levantamento fotográfico da área e do entorno; 7 - Levantamento de desejos e de expectativas da comunidade por meio de oficinas participativas; 8 - Sistematização dos desejos e expectativas em programa de necessidades; 9 - Eleição de prioridades do programa de necessidades sistematizado, por meio de oficinas participativas; 10 - Apresentação e avaliação para aprovação do estudo preliminar, por meio de oficina participativa; 11 - Desenvolvimento do estudo preliminar e aprovação final, por meio de oficina participativa.

Os levantamentos se efetivaram com planejamento prévio de todas as atividades no Laboratório de Projetos (LabProj) do curso de Arquitetura e Urbanismo da UNESC, envolvendo acadêmicos e professores dos cursos de Arquitetura, Engenharia Civil e Engenharia de Agrimensura. Após o reconhecimento do lugar, por meio de visitas in loco e de leitura do material cadastral fornecido pela Prefeitura Municipal de Forquilhinha, foram definidos os limites da área a ser feito o levantamento planialtimétrico e a varredura fotográfica. Ao mesmo tempo, se iniciou a formação da rede de representações institucionais e de lideranças para auxiliar na mediação com a população local, antes e durante as oficinas participativas.

Em seguida, no LabProj, detalhou-se a metodologia das oficinas, que foram objeto de muita discussão entre a equipe, já que o sucesso das mesmas dependia do entendimento claro que os acadêmicos e professores teriam na condução do processo, para que a população efetivamente se sentisse confiante em participar e contribuir. Para a realização das oficinas, traçou-se um esquema que envolvia a ação inicial dos atores mediadores locais: ONG Coletivo Cultural Catavento, lideranças da Associação de Moradores dos bairros Nova York, Ouro Negro e Vila Franca, Associação de Pais e Amigos dos Excepcionais (APAE), Cooperativa Pioneira de Eletrificação (COOPERA) e agentes públicos, representados pelo prefeito, vice-prefeito e alguns secretários municipais.

Até a etapa de apresentação do estudo preliminar, foram definidas cinco oficinas com a comunidade: 
12. Oficina: Das Percepções dos Problemas e Potencialidades em pequenos grupos;

$2^{\mathrm{a}}$. Oficina: Das Proposições para a área pública em pequenos grupos;

$3^{\text {a }}$. Oficina: Leitura dos Painéis e definição Dos Usos e Espaços no grande grupo;

$4^{\text {a }}$. Oficina: Do Programa e da Maquete do terreno no grande grupo;

5 a . Oficina: Do Estudo Preliminar no grande grupo.

As três primeiras oficinas tiveram como tema proposto pela equipe do projeto "Desejos do Conviver". A metodologia aplicada consistiu em organizar os participantes em pequenos grupos (quatro grupos com até 15 participantes) para traduzir as expectativas e desejos quanto às atividades e aos espaços requeridos para esportes, cultura, recreação e lazer, por meio de textos curtos em tarjetas expostas em painéis, nas duas primeiras oficinas, e reunidos e discutidos no grande grupo, na terceira oficina (esta, com cerca de 60 participantes).

De acordo com a metodologia, a quarta oficina teve como objetivo permitir associar e discutir com a comunidade, reunida em grande grupo, sobre o programa prédefinido e votado na terceira oficina, relacionando-o com o espaço disponível da área do projeto, por meio de uma maquete previamente confeccionada pela equipe, com base no levantamento planialtimétrico, na escala 1/250. A intenção era de facilitar a visualização do que o programa poderia requerer de área e confrontar esta demanda com a área disponível do terreno.

A quinta oficina, que reuniu cerca de 55 participantes, compreendeu a apresentação do estudo preliminar se utilizando da apresentação de um vídeo com imagens 3D da proposta espacial e de uma planta de implantação geral. O uso das imagens 3D, associadas com a planta de implantação foi uma solicitação dos participantes durante a quarta oficina, pois argumentaram que esta seria a melhor forma de entenderem o projeto.

\section{RESULTADO E DISCUSSÃO}

O processo desenvolvido com a comunidade dos bairros Nova York, Ouro Negro e Vila Franca nos permitiu avaliar a aplicação da metodologia e os resultados que se pode construir em cada etapa, a partir do modo como se deu a aplicação da mesma nas cinco oficinas participativas realizadas até aqui. A maior interação com a comunidade se deu 
com a realização das três primeiras oficinas. Estas foram fundamentais para que a equipe do projeto construísse um clima de confiança mútua.

Entre 30 e 60 pessoas da comunidade participaram destas oficinas, tendo sempre presentes representantes do poder público municipal e das entidades sociais e instituições locais. Participaram crianças, jovens, adultos e idosos, que contribuíram com a construção do programa de atividades do espaço público a ser projetado. Três oficinas foram realizadas no segundo semestre de 2018, uma no final do primeiro semestre de 2019 e outra, no final do segundo semestre de 2019. Antes do início das oficinas, houve um evento de apresentação da metodologia para a comunidade, que deu início ao processo participativo. Todas as reuniões ocorreram na sede do Centro Comunitário do bairro Nova York, localizado junto da área objeto do trabalho.

Previamente, a equipe realizou uma sequência de reuniões no LabProj para definir uma metodologia de aproximação com a comunidade. Estabeleceu-se três momentos principais para se alcançar o objetivo de definição do programa de necessidades do projeto: de problematização, de categorização e de priorização, sempre conduzindo o grupo a refletir sobre as possíveis formas de contribuir para resolução dos problemas apontados, obter um quadro geral das contribuições, agrupando em temas e reduzindo a complexidade das informações, e priorizar os temas discutidos, afim de que se pudesse atingir um certo nível de conclusão.

A problematização compreendeu atividades preparatórias de escritório, desenvolvidas no LabProj, e atividades de campo. Para dar início à construção da metodologia, foram indicadas, pelos professores aos bolsistas e voluntários participantes do projeto, a leitura das bibliografias referenciadas neste artigo. Na sequência dessas leituras, ocorreram debates que propiciaram a construção de um texto descritivo de detalhamento do que a equipe deveria providenciar para preparação de cada etapa, como um roteiro prévio a ser seguido e que foi sendo complementado à medida que o processo avançava. Para a preparação da primeira oficina participativa, algumas atividades foram definidas:

1 - Reunião prévia da coordenação do projeto com lideranças locais, representantes da ONG Coletivo Cultural Catavento e da Prefeitura para apresentação da metodologia. Esta reunião ocorreu na sede da Prefeitura Municipal de Forquilhinha.

2 - Visita de campo para reconhecimento prévio do lugar e da comunidade pelos membros da equipe do projeto. Esta visita ocorreu no início do mês de junho de 2018, junto com a saída de campo da etapa de Grupos Interfases das disciplinas de projeto do 
curso de Arquitetura e Urbanismo, que estava trabalhando Forquilhinha como recorte urbano do semestre. Nesta saída de campo, os alunos da equipe do projeto receberam uma cópia da planta cadastral do recorte para fazerem anotações de localização das fotos, das suas primeiras impressões do lugar e também dos relatos de representantes da diretoria da Associação de Moradores do bairro Nova York.

3 - Delimitação da área a ser realizado o levantamento planialtimétrico pelos bolsistas do curso de Engenharia e Agrimensura e Cartografia. A partir da delimitação estabelecida após a visita, o levantamento foi concluído ao final de outubro de 2018.

4 - Preparação do material da metodologia a ser explanada no evento de apresentação do projeto para a comunidade, realizado no dia 06/09/2018.

5 - Preparação dos instrumentos e dinâmicas da problematização a ser trabalhada na primeira oficina participativa. Essa preparação compreendeu atividades de planejamento e preparação de material a serem utilizados na oficina. Consistiu de material de apresentação e explicação da metodologia de trabalho, que foi feita logo no início da oficina, e do material a ser disponibilizado para as pessoas poderem se manifestar de acordo como o que havia sido colocado no início da apresentação. Os participantes puderam, logo após a apresentação da metodologia, sugerir adequações e formação dos grupos. Orientou-se a comunidade para que cada grupo fosse o mais heterogêneo possível, em termos, de idade, gênero e relações de vizinhança. Os bolsistas e voluntários da equipe do projeto participaram como monitores de cada grupo, auxiliando na preparação dos painéis e no esclarecimento de dúvidas dos procedimentos a serem desenvolvidos em cada oficina. A problematização se concluiu com a realização da primeira oficina, e a categorização e a priorização foram trabalhadas na sequência, durante a segunda e terceira oficina.

Cada etapa definida na metodologia culminou com um resultado concreto, cujo objetivo de alcançá-lo era colocado no início de cada reunião. E a cada reunião se repassava, de forma breve, o que se alcançou na etapa anterior. O resultado do primeiro encontro foi de conhecimento entre as partes e do entendimento dos objetivos que todos deveriam atingir em cada etapa até poder se chegar ao objetivo geral, de elaboração da proposta de projeto para área pública do bairro Nova York. Também foram definidas as datas duas primeiras oficinas participativas. No primeiro encontro, participaram cerca de 35 pessoas (vide Figura 02).

Figura 02 - Evento de Apresentação do Projeto - 06/09/2018 


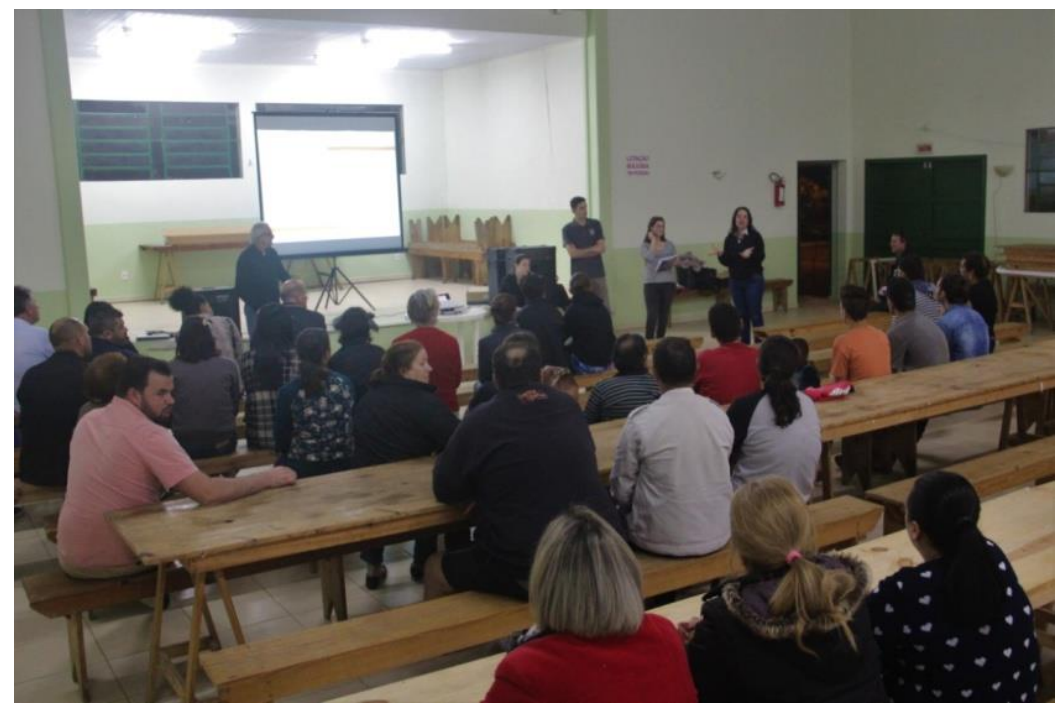

Fonte: equipe do projeto (2018).

No segundo encontro, deu-se a primeira oficina participativa, intitulada Oficina "Desejos do Conviver", realizada em 27 de setembro de 2018. Os trabalhos foram desenvolvidos seguindo os seguintes passos:

1 - Power Point dos objetivos, da metodologia e da programação, apresentado em datashow. A definição de termos técnicos ou que a equipe julgou ser importante definir, foram explicados no decorrer da apresentação inicial. Após a apresentação e explanação da programação e das dinâmicas a serem trabalhadas, foi estabelecido um tempo para os participantes poderem tirar dúvidas ou apresentar sugestões de encaminhamentos. Esgotado este tempo, passou-se para a fase de aplicação das dinâmicas da oficina, com intervalos de tempo pré-estabelecidos, para que o total da reunião não ultrapassasse o limite máximo de duas horas.

2 - Aplicação do questionário de identificação dos participantes. Preparado previamente pelos bolsistas e por eles aplicado, consistia em seis questões para que se pudesse ter um panorama dos perfis de moradores dos bairros envolvidos no projeto (vide Figura 03). 
Figura 03 - Modelo do Questionário de Identificação

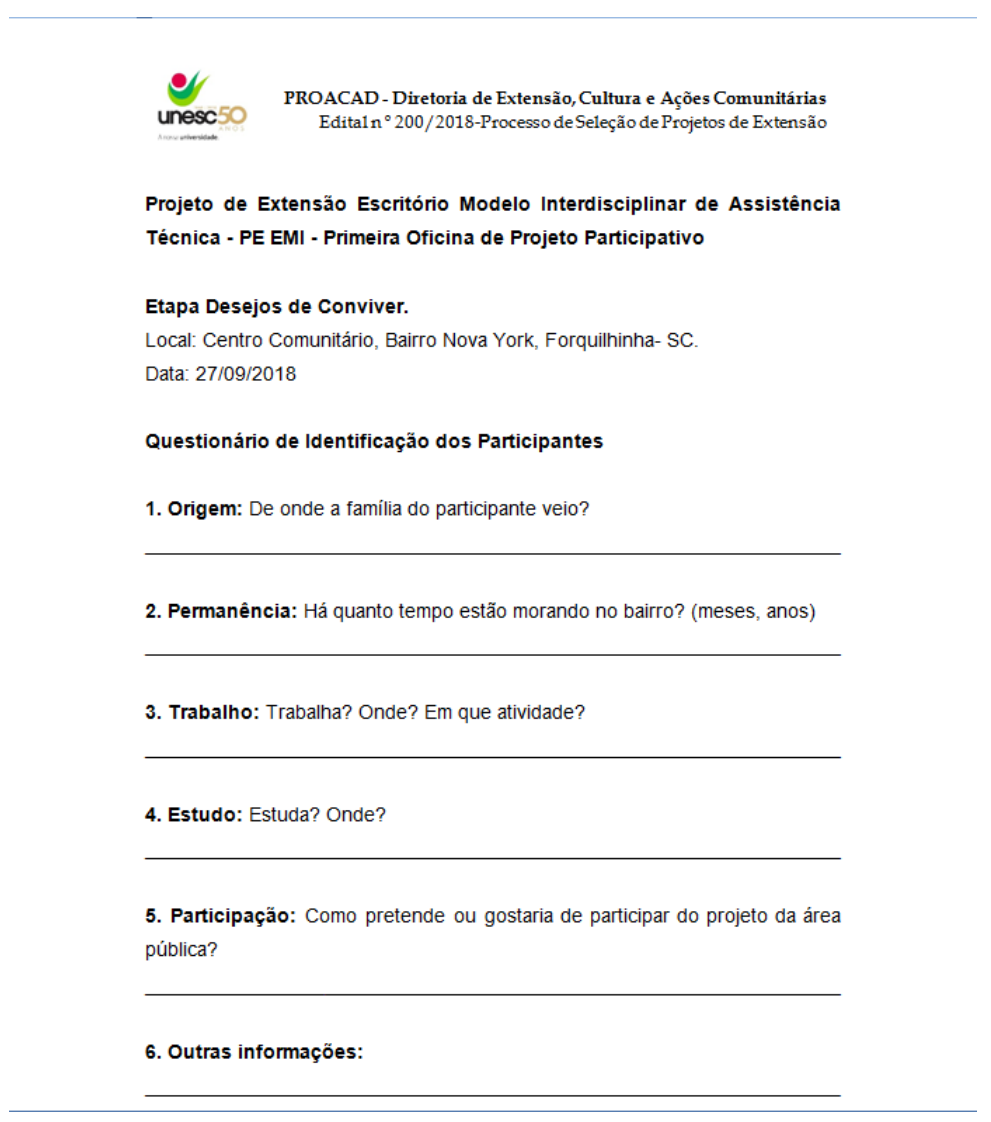

Fonte: equipe do projeto.

3 - A construção da problematização teve início propriamente com a segunda dinâmica, com os participantes reunidos em quatro grupos de cerca de 15 membros cada (vide Figura 04). Como ponto de partida, a coordenação do projeto apresentou e explicou as definições dos termos a serem trabalhados em cada grupo. Em seguida, cada bolsista da equipe, auxiliado por um monitor da administração municipal ou da ONG Coletivo Cultural Catavento, colocou um painel de papel craft no centro de cada grupo que foram previamente organizados em semicírculo. Cada grupo recebeu canetas e cartelas em branco para que pudessem discutir e responder às questões que foram apresentadas pela coordenação do projeto. Ao todo, foram quatro painéis com tempo determinado para início e finalização, onde cada participante deveria apontar três itens em cada folha de papel craft, relativos ao seu bairro:

1 - Percepção dos Problemas e das Precariedades do seu bairro.

2 - Percepção do Atrativos do seu bairro.

3 - Percepção das Necessidades do seu bairro.

4 - Percepção da Manutenção do que é positivo no seu bairro. 
Figura $04-1^{\text {a }}$. Oficina Participativa: Painel de Percepção dos

Problemas e das Potencialidades

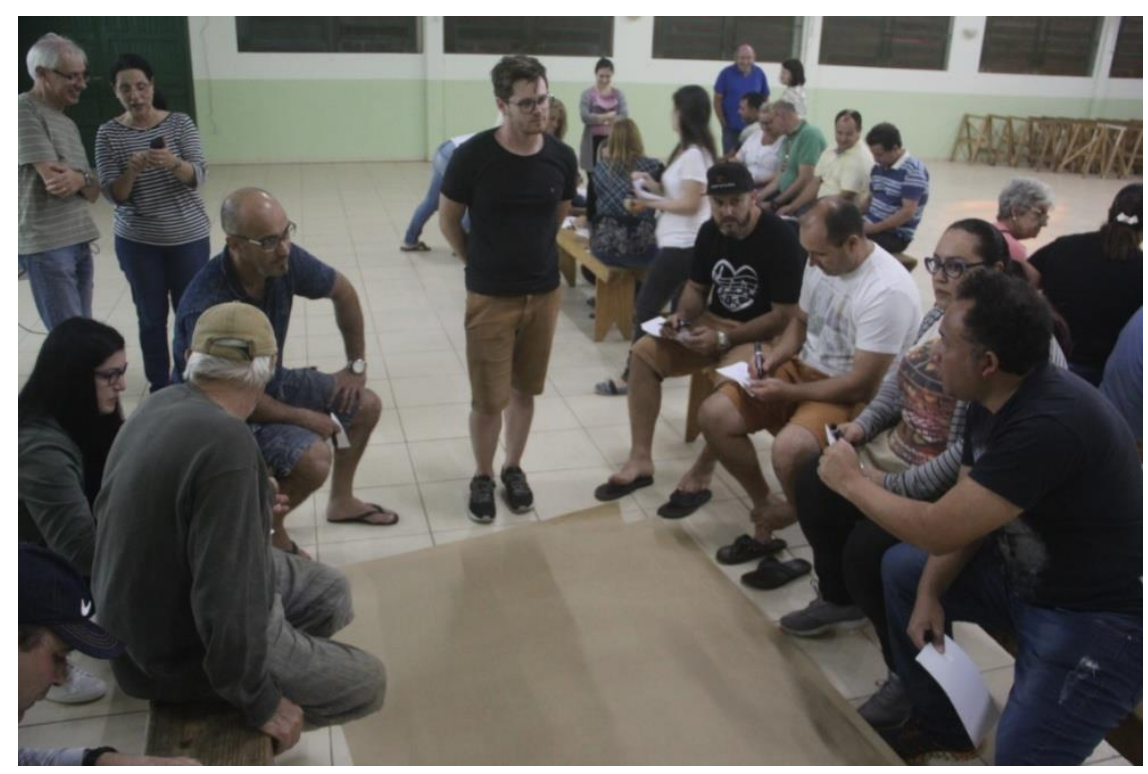

Fonte: equipe do projeto.

Ao término do tempo do último painel, todos foram montados, e lidas as várias cartelas escritas em cada um para todos os participantes da reunião, sem se fazer qualquer classificação das respostas a priori. Concluída a oficina, os painéis foram fotografados e recolhidos pela equipe do projeto e trazidos para o LabProj, onde foram analisados a fim de se propor uma classificação prévia dos itens encontrados em cada painel para ser apresentado e discutido na segunda oficina.

$\mathrm{O}$ terceiro encontro tratou da segunda oficina participativa (vide Figura 05). O tema principal desta oficina foi de Proposições para a área específica do projeto. Novamente os participantes receberam as orientações das dinâmicas que seriam desenvolvidas na reunião, bem como a definição prévia dos termos com que se iriam trabalhar. Foi dado um espaço de tempo para que as pessoas pudessem esclarecer dúvidas ou sugerir encaminhamentos. Em seguida, foram formados três grupos com cerca de 15 membros cada, que receberam canetas, cartelas e folhas de papel craft para os painéis de Proposições por faixas etárias (crianças, jovens, adultos e idosos) e por gênero, no sentido de se contemplar atividades não só para os homens, já que a maioria dos equipamentos existentes na cidade, em grande parte se resumiam a campos de futebol. Concluídos os painéis, estes foram reunidos e apresentados ao grande grupo, sem que se fizesse nenhuma 
classificação a priori. Finalizada a reunião a equipe do projeto fotografou e recolheu os painéis para sistematização no LabProj.

Figura $05-2^{\mathrm{a}}$. Oficina Participativa:

Painel de Proposições

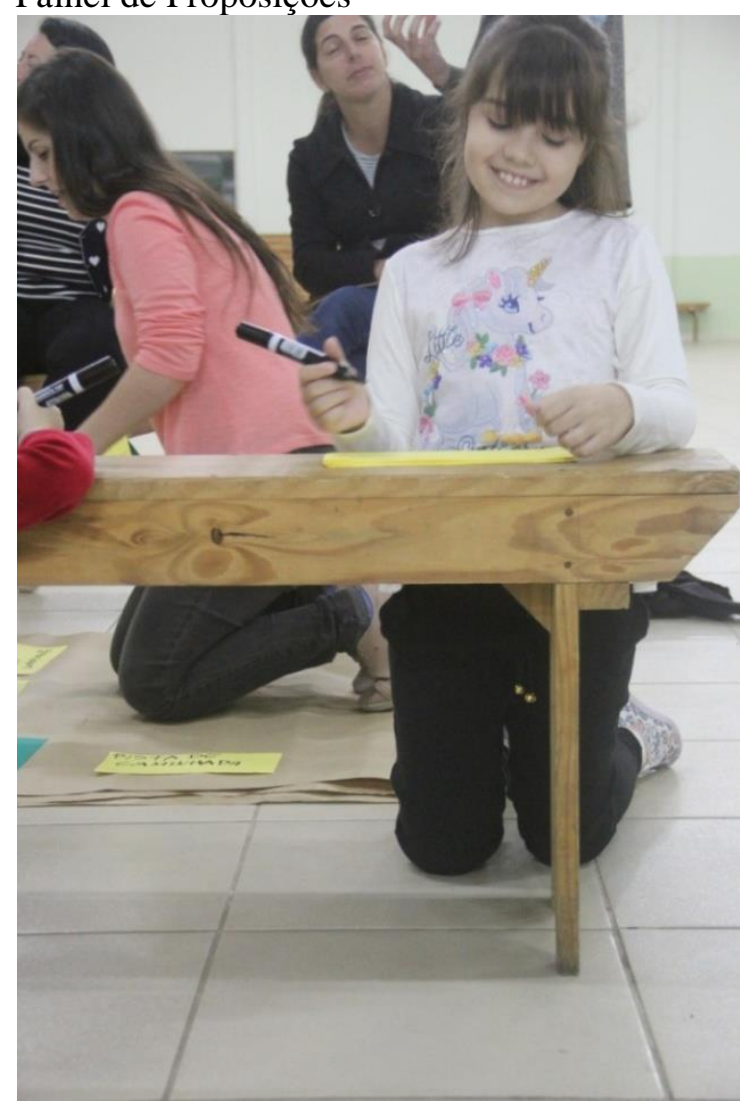

Fonte: equipe do projeto.

$\mathrm{O}$ quarto encontro tratou da terceira oficina, que teve como principal objetivo apresentar a sistematização dos resultados dos painéis das duas primeiras oficinas, previamente fotografados pela equipe no LabProj e montados em um Power Point, além de se proceder com a votação das prioridades para que a equipe pudesse traduzi-las em um programa de necessidades. A coordenação do projeto, logo no início da reunião reapresentou os conteúdos de cada painel, tanto os de problematização, quanto os de proposição. Ambos foram sistematizados e categorizados, mas a oficina se concentrou nos painéis de proposição, já que os de problematização diziam respeito a outras questões do bairro que não tinham a ver diretamente com o que se pretendia para a área objeto do projeto, mas poderiam fornecer informações de avaliação das políticas públicas da administração municipal para os bairros envolvidos.

Em seguida, a coordenação apresentou os itens já sistematizados e categorizados, na forma de cinco quadros de proposições para: crianças; jovens; adultos; idosos e por 
gêneros (vide Figura 06) e de gráficos que apontavam em ordem decrescente os itens sistematizados que mais vezes se repetiram entre todos os grupos.

Figura $06-3^{\text {a }}$. Oficina Participativa: Sistematização e

Categorização dos resultados das duas primeiras oficinas

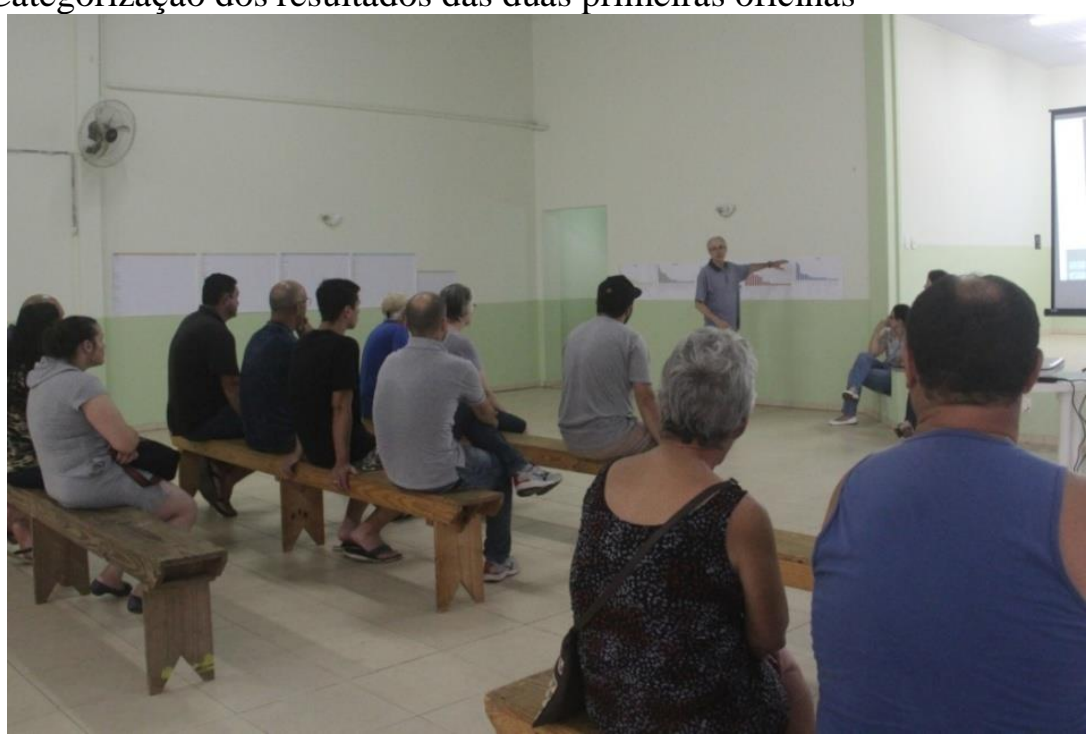

Fonte: equipe do projeto.

A terceira oficina finalizou com a votação das Prioridades, o que foi feito seguindo a dinâmica de votação, pela qual cada participante assinalava três itens de cada quadro das Proposições. Assim, os bolsistas, auxiliados por monitores locais, entregavam 15 adesivos para que cada participante pudesse colar diretamente sobre os cinco quadros fixados na parede do salão (vide Figura 07). Ao término da votação, a coordenação do projeto explicou o procedimento de sistematização que seria feito pela equipe do projeto, no LabProj. No encerramento da reunião, os quadros com o resultado das votações foram fotografados e recolhidos pela equipe do projeto.

Após o trabalho de sistematização do resultado da votação, a equipe procurou filtrar termos que se repetiam ou que tinham significados muito próximos ou atividades que poderiam ser agrupadas, como por exemplo, "quadra poliesportiva" e "quadra de futebol de salão". 
Figura $07-3^{\text {a }}$. Oficina Participativa: Momento da Votação

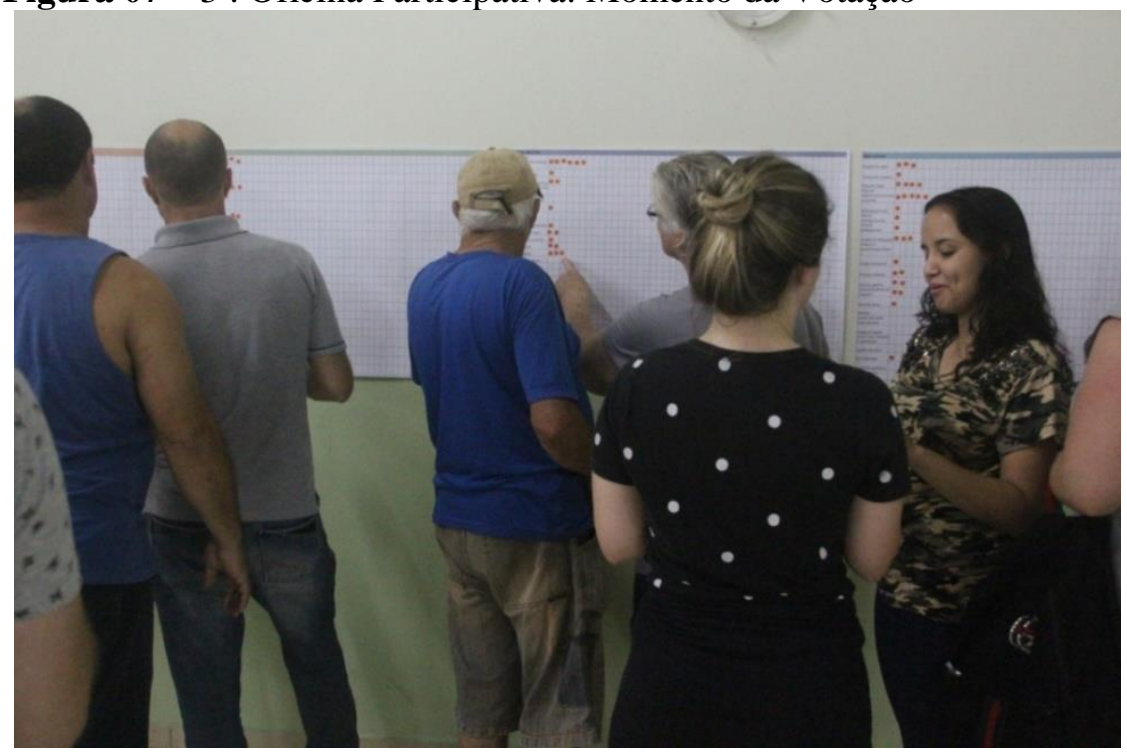

Fonte: equipe do projeto.

Essa triagem foi feita no LabProj e preparada uma apresentação para discussão com a comunidade no quinto encontro, onde se realizou a quarta oficina e se definiu o programa de necessidades, derivado do gráfico com o resultado da votação (vide Figura 08), apresentado no início da oficina. A comunidade, após a equipe ter apresentada a proposta de agrupamento de alguns itens que se aproximavam ou se repetiam, definiu o seguinte programa de necessidades para ser considerado na etapa de desenvolvimento do partido do projeto de urbanização e dos equipamentos da área:

1. Pista de caminhada, atletismo e ciclovia;

2. Quadra Poliesportiva;

3. Quadra de futebol suíço;

4. Quadra de Areia para Vôlei, futebol e futevôlei;

5. Quadra coberta para dança e zumba;

6. Biblioteca com salas para cursos, oficinas, auditório e cinema;

7. Sede da Associação dos moradores;

8. Sede para o clube de mães e idosos;

9. Playground adaptado para a inclusão social;

10. Academia pública;

11. Cancha de bocha;

12. Pista de Skate;

13. Locais para a arte de grafite; 
14. Reserva com árvores e plantas;

15. Quiosques;

16. Mesas para diversos jogos como xadrez, baralho e dominó;

17. Concha acústica;

18. Bolsões de estacionamento.

Figura $08-4^{\mathrm{a}}$. Oficina Participativa: Gráfico apresentado do Resultado da Votação da $3^{\text {a }}$. Oficina.

RESULTADOS - EQUIPAMENTOS

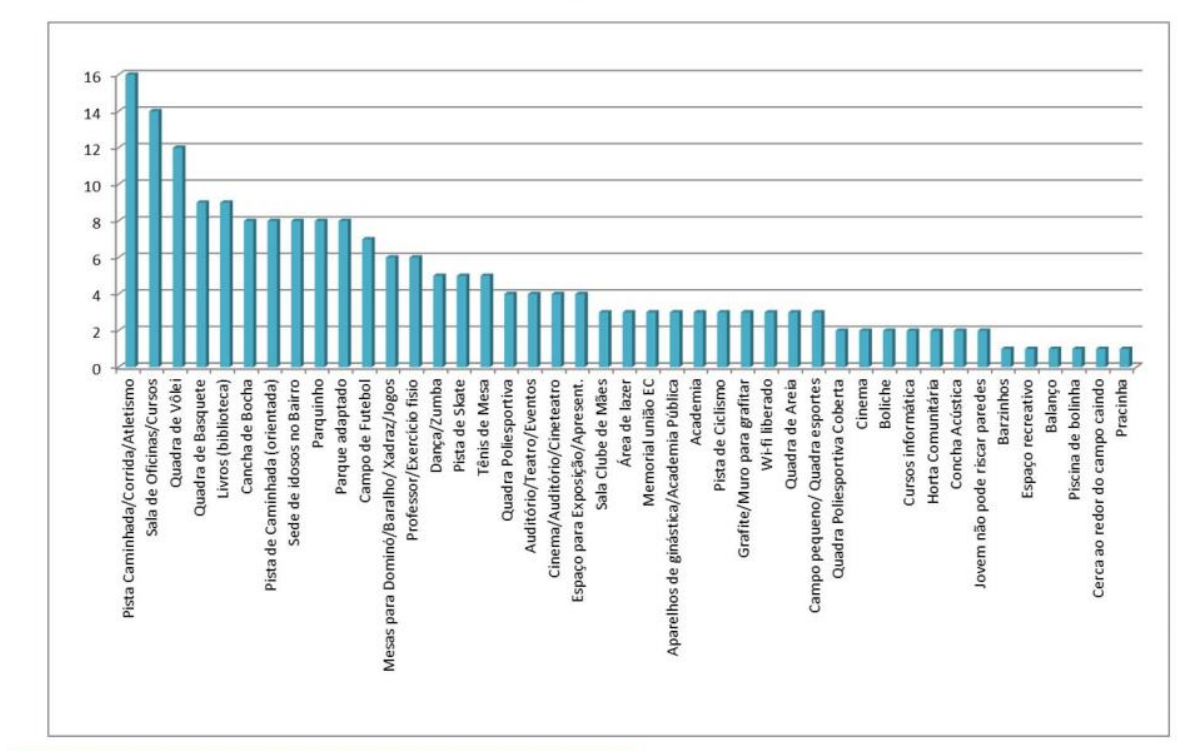

Fonte: equipe do projeto (2019).

Entre a quarta e a quinta oficina, transcorreu um semestre. No segundo semestre de 2019, a equipe trabalhou o tempo todo no LabProj ou no Ateliê Central do curso de Arquitetura e Urbanismo para desenvolver o partido do projeto, com base no programa definido pela comunidade, tendo como material complementar, para definição da implantação de cada equipamento, as fotos tiradas do local e a maquete física do terreno e entorno, na escala $1 / 250$.

A equipe de bolsistas e voluntários foram orientadas pelos professores responsáveis pelo projeto para pesquisarem, em revistas e sites, projetos de referência que contemplassem programa e área similar ao que se tinha no bairro Nova York. Em paralelo, foram sendo desenvolvidos os primeiros estudos em planta de implantação e cortes gerais do partido e preparada as bases de representação nos programas Auto Cad e Sketch Up 
(vide Figura 09), a partir do levantamento topográfico fornecido pelos professores e alunos bolsistas do curso de Engenharia de Agrimensura e Cartográfica.

Figura 09 - Estudo do partido de implantação

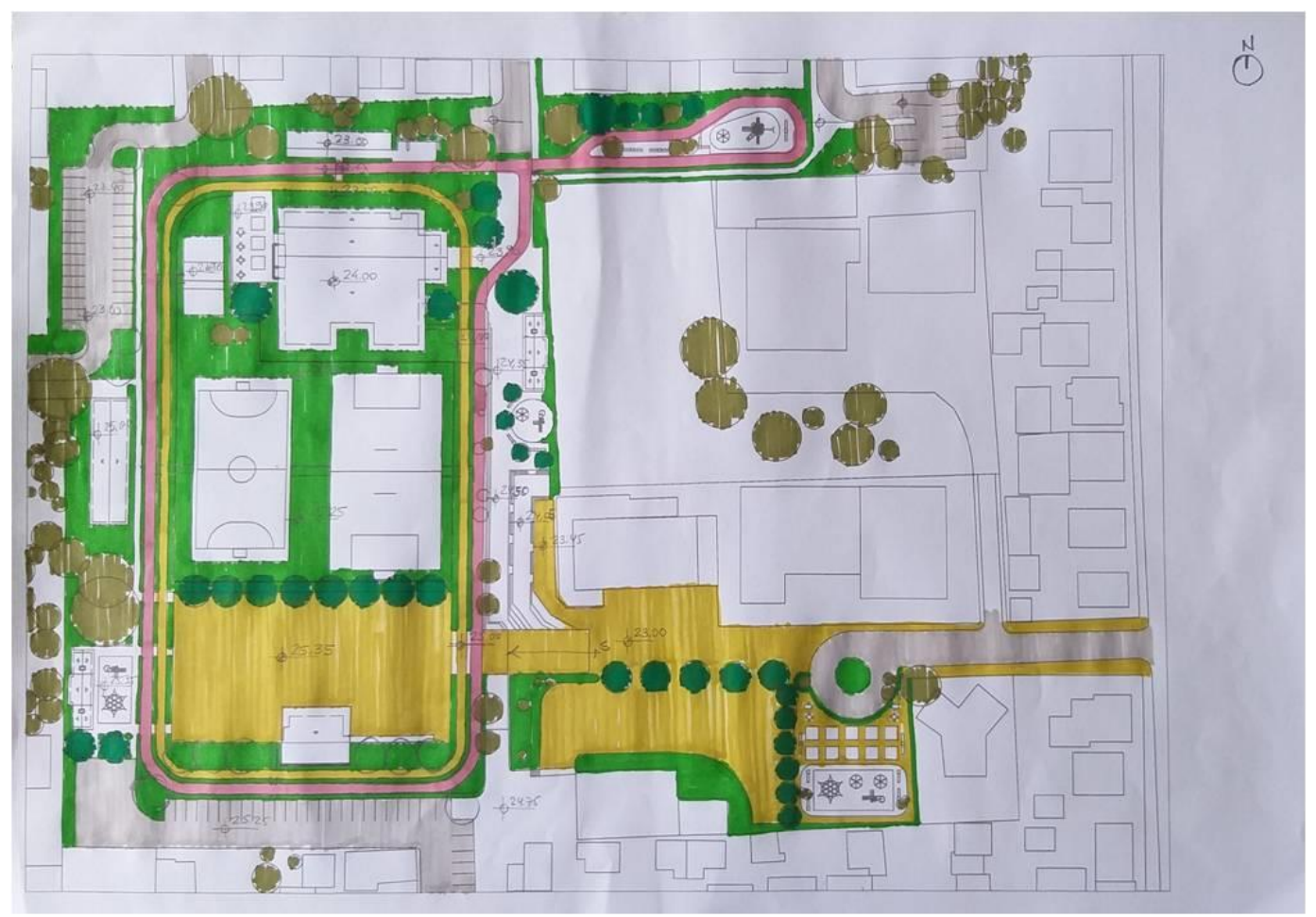

Fonte: equipe do projeto (2019).

À medida que as ideias do partido foram se concretizando no estudo de implantação, solicitou-se aos alunos bolsistas de fases mais adiantadas para iniciarem os projetos dos equipamentos, como quiosques, churrasqueiras, mesas de jogos, brinquedos de parques infantis, quadras esportivas, canchas de bocha, concha acústica e o centro de atividades multiuso, que contempla a sede da Associação de Moradores, biblioteca, salão de dança e salas para diversas atividades do clube de mães, dos idosos e dos jovens. $\mathrm{O}$ resultado desse trabalho foi apresentado em Power Point com imagens em planta e vistas de vários pontos de observação construídas no Sketch $U p$, prancha impressa e vídeo, na $5^{\text {a }}$. oficina participativa, realizada em 10 de dezembro de 2019 (vide Figura 10). Nessa apresentação o estudo preliminar foi colocado em discussão com a comunidade que, ao final, o aprovou com algumas sugestões de alteração de localização de equipamentos.

O projeto será concluído no final do primeiro semestre de 2020, com a entrega da maquete física da implantação e os desenhos do estudo preliminar dos equipamentos propostos conforme aprovação na oficina do estudo preliminar. Ficará a cargo da 
Prefeitura Municipal de Forquilhinha dar sequência ao detalhamento dos projetos para orçamento e programação da execução do mesmo por etapas.

Figura 10 - Perspectiva dos Quiosques com Churrasqueiras, parque infantil e ciclovia

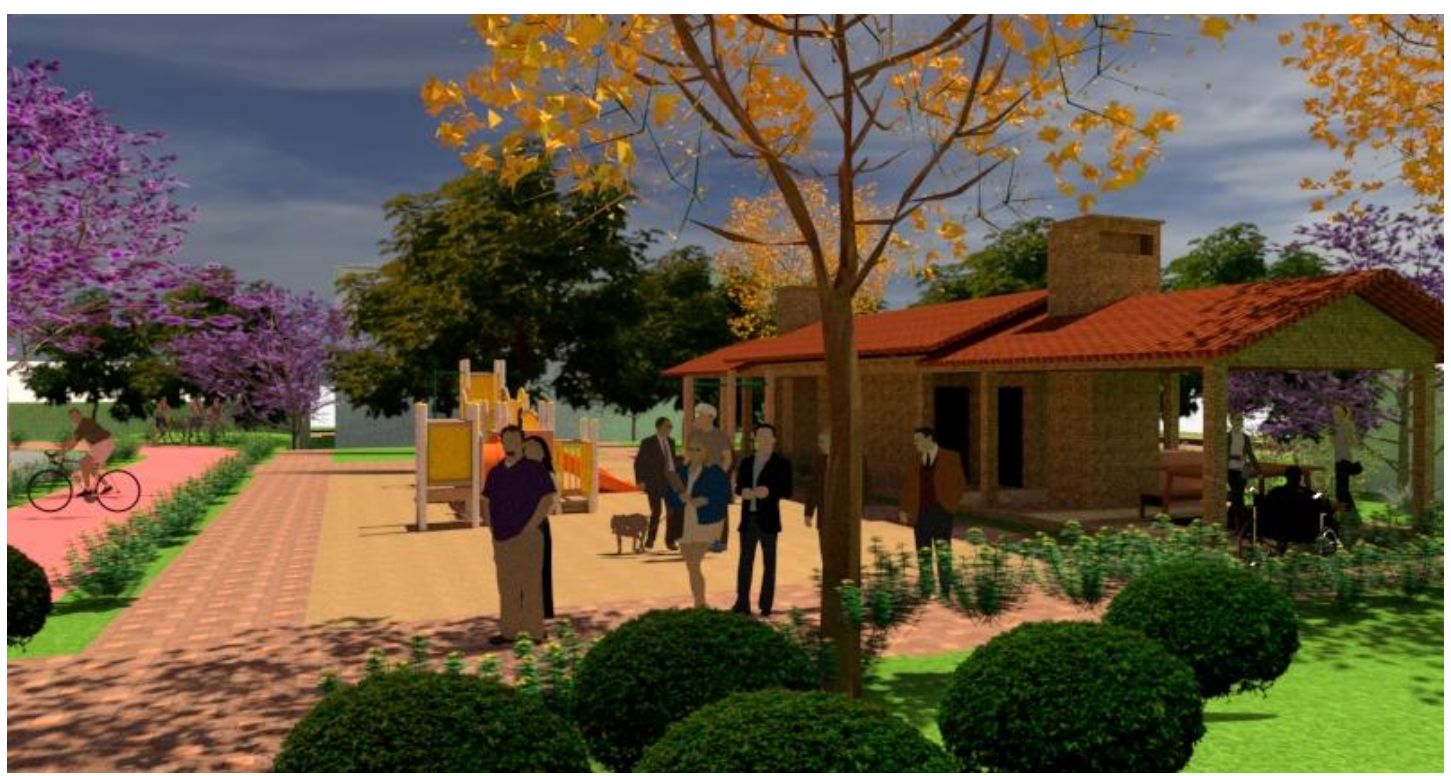

Fonte: equipe do projeto (2019).

\section{CONCLUSÕES}

A metodologia das oficinas participativas foi o foco central do processo de construção do projeto de forma integrada com as representações institucionais, lideranças locais, população e equipe do projeto. Para a equipe, o resultado dependia da condução do processo de percepção e definição das necessidades que teriam que ser obra da comunidade local. A diversidade de faixas etárias também concorreu positivamente para que se pudesse construir um programa de contemplação mais ampla. Embora se imaginasse que haveria maior número de participantes em cada oficina, o número médio que oscilou entre 30 e 60 pessoas foi adequado para que se pudesse distribuir a equipe dos bolsistas e voluntários para atender a um número médio máximo de 15 participantes da comunidade por grupo. Isso facilitou as explicações e os esclarecimentos de dúvidas, tanto no momento de preenchimento das cartelas, quanto da votação das proposições de atividades e de espaços.

A princípio se havia pensado na possibilidade de se trabalhar, na metodologia, com desenhos, além dos textos, mas a decisão de trabalhar apenas com textos sobre cartelas foi mais adequado para o público diversificado, tanto em faixa etária, quanto grau de instrução. Neste sentido, o questionário aplicado na primeira oficina, para se conhecer 
os perfis dos participantes, foi valioso quanto à decisão de se descartar o emprego do desenho para se obter as percepções da população sobre o lugar onde mora e sobre o terreno objeto da intervenção.

A apresentação do partido e estudo preliminar propostos, na quinta oficina participativa, junto à comunidade e lideranças locais, foi positiva, tanto é que houve repercussão muito forte nas mídias locais, antes, durante e após a oficina, no sentido de valorizar tanto o resultado, quanto o processo de participação na elaboração do projeto. Essa repercussão se fez sentir também junto à administração municipal, que mostrou interesse em aplicar a metodologia em projetos mais amplos para a cidade de Forquilhinha, questão esta que se encontra em tratativas entre representantes da Prefeitura Municipal e o Curso de Arquitetura e Urbanismo da UNESC.

Para os acadêmicos bolsistas e voluntários dos cursos envolvidos, a experiência se mostrou muito rica em muitos aspectos. A começar pela oportunidade que tiveram de experimentar um processo de elaboração de projeto que ainda não é comum na realidade da maioria dos nossos municípios e de qualquer nível de administração pública. Ao mesmo tempo que tiveram oportunidades de aplicar os conhecimentos e habilidades construídas em suas carreiras acadêmicas, puderam vivenciar as etapas que um processo desta magnitude envolve de planejamento até se poder chegar ao projeto efetivamente.

\section{AGRADECIMENTOS E APOIO}

Diretoria de Extensão, Cultura e Ações Comunitárias da UNESC.

Prefeitura Municipal de Forquilhinha.

Coletivo Cultural Catavento.

Associação de Moradores dos Bairros Nova York, Ouro Negro e Vila Franca.

Associação de Pais e Amigos dos Excepcionais de Forquilhinha - APAE

Cooperativa Pioneira de Eletrificação Rural - COOPERA. 


\section{REFERÊNCIAS}

ABRAHÃO, S. L. O espaço público urbano na perspectiva de Carlos Nelson Ferreira dos Santos. Arquitextos, São Paulo, ano 17, n. 204.04, mai. 2017. Vitruvius. Disponível em: https://www.vitruvius.com.br/revistas/read/arquitextos/17.204/6560. Acessado em: 18 fev. 2020.

ALEXANDER, C.; ISHIKAWA, S.; SILVERSTEIN, M. Uma linguagem de padrões: a pattern language. Porto Alegre: Bookman, 2013.

FARIA, J. A. Projeto Urbano e Democracia Técnica. III ENCONTRO DA ASSOCIAÇÃO NACIONAL DE PESQUISA E PÓS-GRADUAÇÃO EM ARQUITETURA E URBANISMO, 3., 2014, São Paulo. Arquitetura, cidade e projeto: uma construção coletiva.

FREIRE, P. Pedagogia da autonomia: saberes necessários à prática educativa. 43. ed. São Paulo: Paz e Terra, 2011.

Extensão ou Comunicação? 16. ed. Rio de Janeiro: Paz e Terra, 2013.

HARVEY, D. Espaços de esperança. 2. ed. São Paulo: Edições Loyola, 2006.

IMAI, C. A utilização de modelos tridimensionais físicos em projetos de habitação social: o Projeto Casa Fácil. Tese (Doutorado). Faculdade de Arquitetura, Universidade de São Paulo, São Paulo, 2007.

LANA, S. M. O arquiteto e o processo de projeto participativo: o caso do RSV. Dissertação (Mestrado). Escola de Arquitetura, Universidade Federal de Minas Gerais (UFMG), Minas Gerais, 2007.

MASCARENHAS, G.; DRUMOND, R.; CAMPOS, T. Para além da sustentabilidade: uma metodologia inclusiva e participativa de projeto. Cadernos de Arquitetura e Urbanismo, v. 19, n. 24-25, p. 209-221, 2012.

RIO DE JANEIRO. Instituto de Administração Municipal. Centro de Pesquisas Urbanas. Quando a rua vira casa: a apropriação de espaços de uso coletivo em um centro de bairro. Coord. Carlos Nelson Ferreira dos Santos e Arno Vogel. 3. ed. Revisada e atualizada. São Paulo: Projeto, 1985.

SANTOS, B. S. Renovar a teoria crítica e reinventar a emancipação social. São Paulo: Boitempo, 2007. 